\title{
Study of the effect of positioning accuracy of system rigidity and part quality in waterjet cutting
}

\author{
Sh. S. Nozirzoda, S. E. Bukhanchenko \\ National Research Tomsk Polytechnic University, Tomsk, Russia
}

\begin{abstract}
This paper discusses ensuring the specified accuracy and quality of processing parts of various shapes by scientifically validatedchoiceof the processing zone, cutting modes, and making adjustments to the control systems of the technological system for waterjet cutting. In the course of experimental studies, the stiffness of the positioning system for the installation of awaterjet cutting tool, the accuracyand quality of processing with waterjet cutting were determined. The influenceof the stiffness of the positioning system of the abrasive waterjet cuttingtool on the accuracyand quality of the surface of the obtained products and the ways to improve accuracy were determined. Based on the results of the study, recommendations to improve the accuracy and quality of partsare given.
\end{abstract}

\section{Introduction}

Modernization of the national economy in the strategy for the development of the Russian Federation until 2020 is a priority urgent task [1]. One of the main branches of the economy is machine-building production. Machine-building production is considered the main branch of the metalworking industry; it occupies a central place in the economy of all developed countries of the world.

Currently, it is necessary to constantly update product ranges to increase the competitiveness of domestic engineering products.Improvement of the competitiveness of domestic engineering products primarily depends on the accuracy and productivity of material processing. Improvement of the accuracy and productivity of processing of metalworking equipment is a complex problem, the solution of which is associated with improving the quality of manufacturing of metal-cutting equipment, fixtures, and tools, maintaining their accuracy characteristics during operation, as well as automation, complex mechanization, and robotization of production [2]. Improving the quality of equipment at the design and production stages is achieved by improving design calculation methods, using modern materials, as well as advanced technology for processing and assembling parts and assemblies. Therefore, precision control in the application of advanced technologies is an urgent task.

Water with an abrasive additive flows at high pressure through a very thin nozzle, cutting stainless steel and its alloys. Waterjet cutting (WJC) allows to perform various manipulations: cutting sheet metal; cutting and perforating profiles; perforating sheet metal of various thicknesses; cutting blanks of various thicknesses and configurations [3]. 
The basis of the method of waterjet cutting is the impact on the material with a mixture of water and abrasive sand. Under the impact of the jet, the material is destroyed, and the part isnot heated, deformed, and does not form a scale as in laser cutting [4].

\section{Materials and research methods}

The process equipment used is a waterjet cutting unit of the TecnocutIdroLine 1740 model. Table 1 shows the main characteristics of the TecnocutIdroLine 1740 installation [5].

Table 1. Main characteristics of the TecnocutIdro Line 1740 installation.

\begin{tabular}{cc} 
Specifications & Value \\
\hline Size of workpieces to be processed & $3800 \times 1400 \mathrm{~mm}$ \\
Height of the processed material & up to $150 \mathrm{~mm}$ \\
Ability to tilt the head and cut at an angle & up to 60 degrees \\
Probe for monitoring the progress axis & $\mathrm{Z}$ \\
Pressure abrasive feed system with hopper & by $330 \mathrm{~kg}$
\end{tabular}

The working medium in this process is water with hydrogen $\mathrm{pH}$ - neutral, under the pressure of 3-4 kg $/ \mathrm{cm}^{2}$. The cutting tool in a waterjet machine is a jet of a mixture of working medium with an abrasive. The abrasive used in this work is garnet sand of the MESH 80 brand. The water consumption is $51 / \mathrm{min}$, and the abrasive consumption is $400 \mathrm{~g} / \mathrm{min}$.

Geometric accuracy is ensured by penetration at a very high level, but during the processing of corners, there might be problems that can be solved by settings of the flow rate. As a rule, in the zone where the jet changes its trajectory, forming a straight or sharp angle, the jet speed and feed rate are reduced [6]. All parameters of the WJC technological system that somehow affect quality factors can be divided into three groups: production, technological, and private (Fig.1).

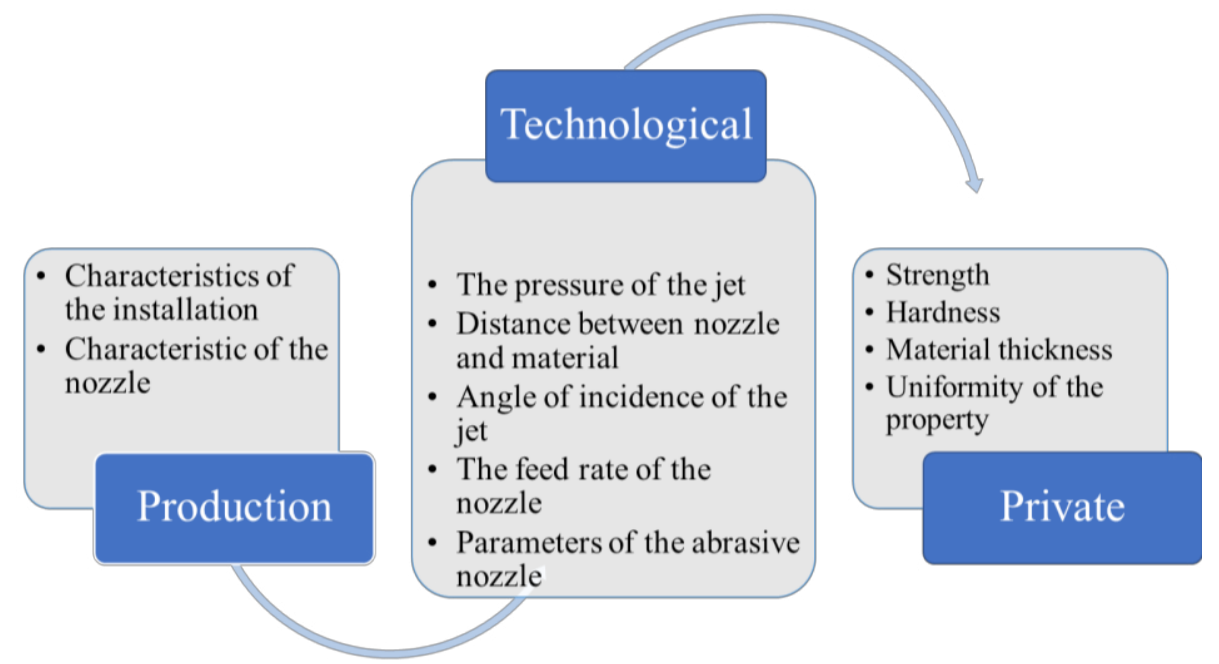

Fig. 1. Relationship between the parameters of the WJC process system and the cut quality factors

The removal of material, when exposed to a jet of abrasive particles, occurs as a result of the interaction of several simultaneous processes: the collision of particles with each other inside the incoming flow; crushing of individual particles; shielding of the treated surface by particles 
bouncing off it; damage to the surface layer of the material as a result of repeated impacts with abrasive particles.

Research methods are divided into two large groups: theoretical and empirical. This division is based on the method used to obtain information: empirical methods are based on observations of the object, and theoretical methods are based on the information obtained [7].

The following types of theoretical methods are used in this work:

- Comparative analysis, i.e., a method of comparing two or more objects of research (phenomena, objects, ideas, results, etc.). As a result of the analysis, the advantages and disadvantages of waterjet installations and waterjet processing are considered.

- Synthesis, i.e., creating a single concept from disparate data put together.

In this work, the following types of empirical methods are used:

- Experiment, i.e., material embodiment of hypotheses and concepts used to confirm or refute them; conducting experimental studies to determine the accuracy and quality of parts treated on a waterjet machine, as well as a number of experiments to study dynamic processes in WJC

- Observation, i.e.,the process of passive cognition of the studied phenomena and objective fixation of the results of perception

- Measurement, i.e., active cognition of phenomena by determining their fundamental characteristics and properties in calculable units ; measurement of the actual dimensions of parts obtained on a waterjet machine

- Comparison, i.e., comparison of objects and phenomena by important characteristics, comparison of the obtained dimensions with the dimensions specified in the working drawing

- Description, i.e., the process of detailed recording of data obtained as a result of the methods listed above.

\section{Main section}

Several experiments were necessary to determine the accuracy and quality of the surface of products manufactured on a waterjet unit. The portal waterjet cutting system was divided into 8 cutting zones. The front wall part is made of structural cryogenic steel 12x18n10t GOST 563272. The front wall part is the support of the window of the robotic installation of ultrasonic control of ofa complex shape product. The part is made of rolled steel with subsequent processing. The main part of the manufacturing process of the front wallpart was performed at the waterjet plant. 36 holes with a diameter of $9 \mathrm{~mm}$ were cut, then the outer and inner contours of the part were processed. Fiveparts were selected as samples. The samples were installed as shown in Figure 2. 


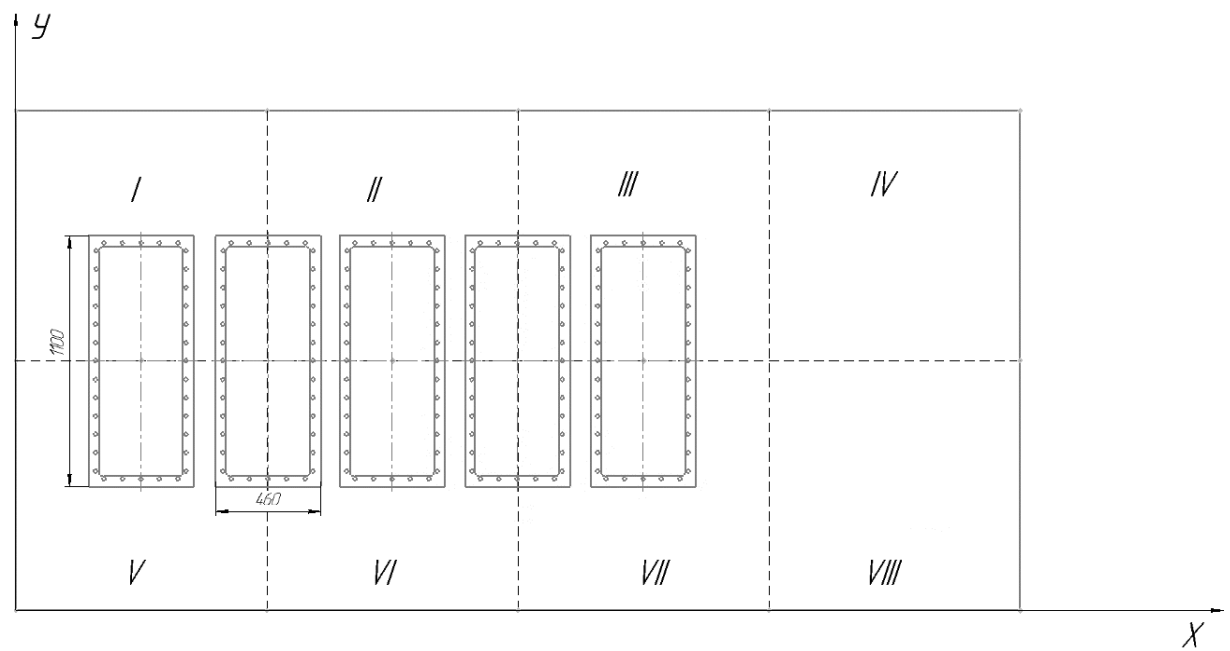

Fig. 2. Diagram of the location of the partsin the cutting zone.

The samples were processed on a waterjet unit with sequential machining. Some dimensions were marked on the selected samples for measurement after the WJC treatment. These are key dimensions that could be applied to an accuracy study. The measured dimensions are shown in the diagram (Fig. 3).

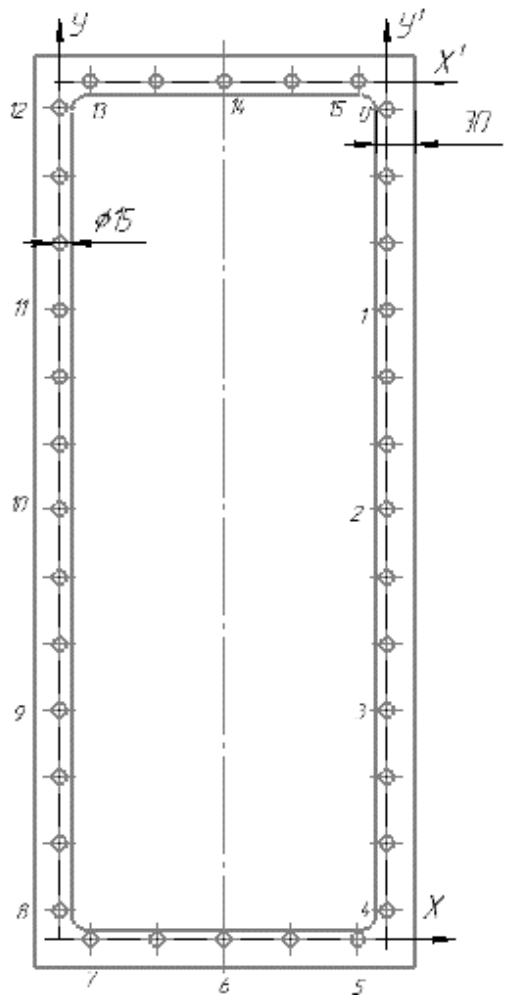

Fig. 3. A processed part on a waterjet installation 
In this paper, we considered 15 diametric dimensions in addition to linear dimensions. Based on the measurement results, changes in deviation from the nominal dimensions on different axes were taken into consideration. Figure 4shows the dependence of the diameter dimensions deviations along the $\mathrm{X}^{1}$ axis(the upper fraction of the part) from the coordinate along the abscissa axis.

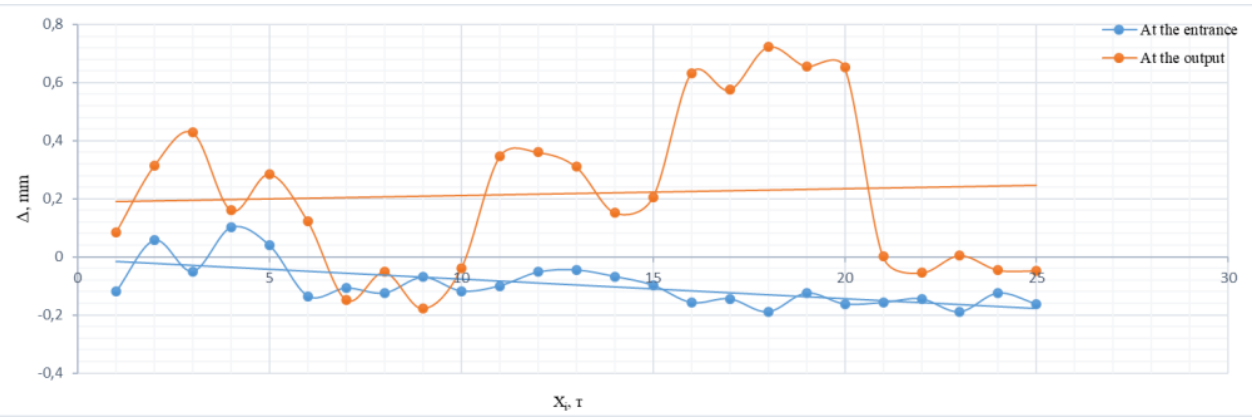

Fig. 4. Dependences of changes in the diameter dimension deviations from the nominal ones on the upper fractionof the part ( $\Delta$-deviations of the diameter dimensions on the $\mathrm{x}$-axis, $\mathrm{mm}$; Xt-coordinates on the $\mathrm{x}$ axis, $\mathrm{m})$.

Figure 5 shows the dependence of the diameter dimensionsdeviations along the $\mathrm{X}$-axis (the lower fractionof the part) from the coordinate along the ordinate axis.

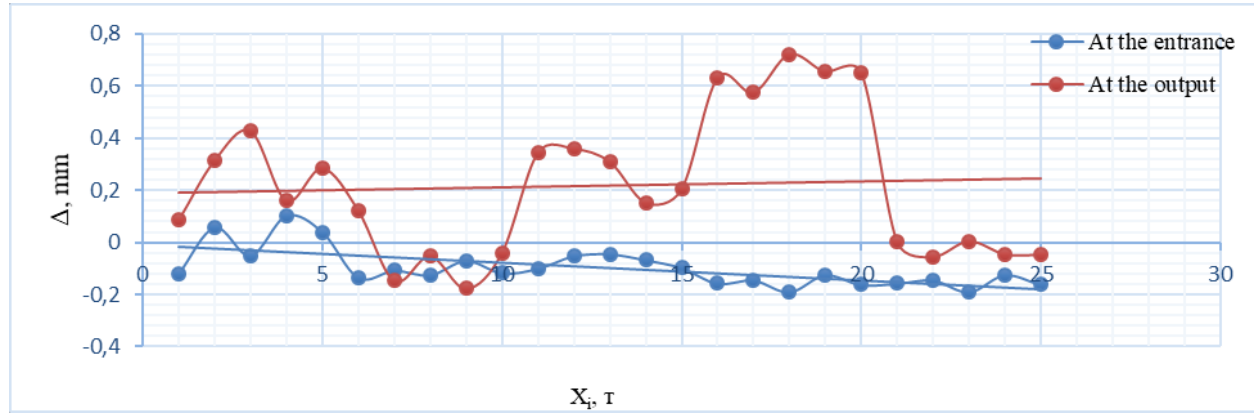

Fig. 5. Dependence of the change in the dimensionsdeviationsfrom the nominal ones on the lower fractionof the part ( $\Delta$-deviations of the diameter dimensions on the $\mathrm{x}$-axis, $\mathrm{mm}$; Xt-coordinates on the $\mathrm{x}$-axis, $\mathrm{m}$ ).

I It can be seen from the above dependenciesthat the largest deviations are observed in part 4 , and the smallest deviations in parts 5 and 2, which were located in zones II and III. Thus, the accuracy of processing the hole is variable: it changes depending on the coordinate on the axis of the abscissa.

Changes in the deviation of the diametric dimensions along the ordinate axis also were considered, as shown in the diagram (Fig. 2). According to the measurement results, changes in the deviation from the nominal dimensions along the $\mathrm{Y}$-axis (right fractionof the part) and $\mathrm{Y}^{1}$ (left frationof the part) were obtained; Figure 6 shows the dependence of the diameter dimensions deviations along the $\mathrm{Y}$-axis(right fractionof the part) and $\mathrm{Y}^{1}$ (left fractionof the part) from the coordinate along the ordinate axis. 


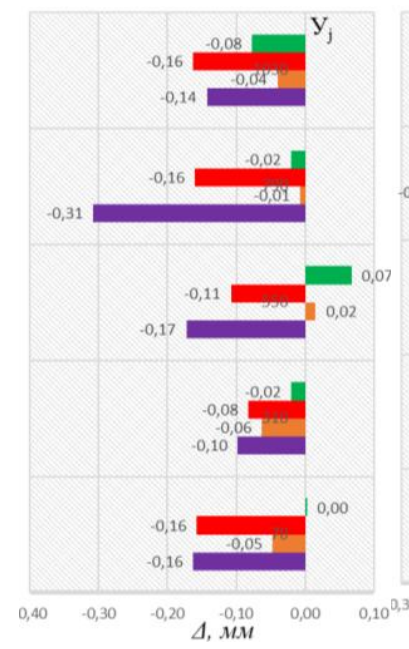

a)

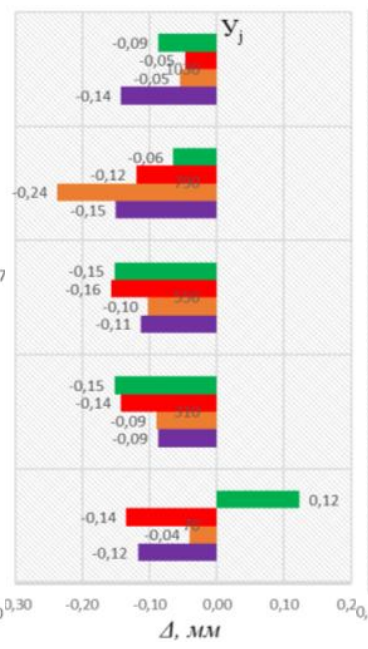

b)

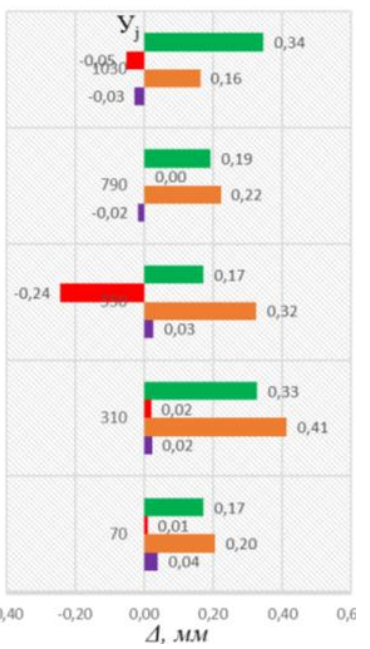

c)

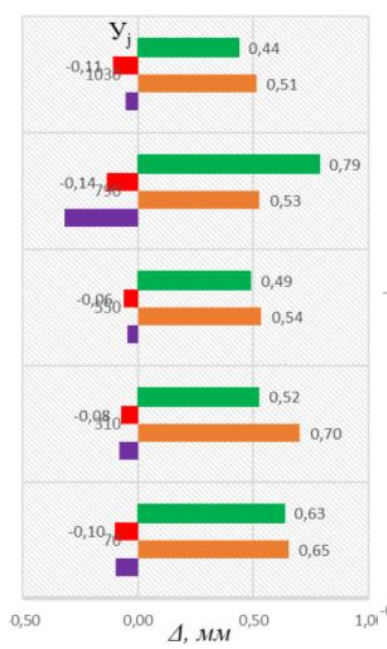

d)

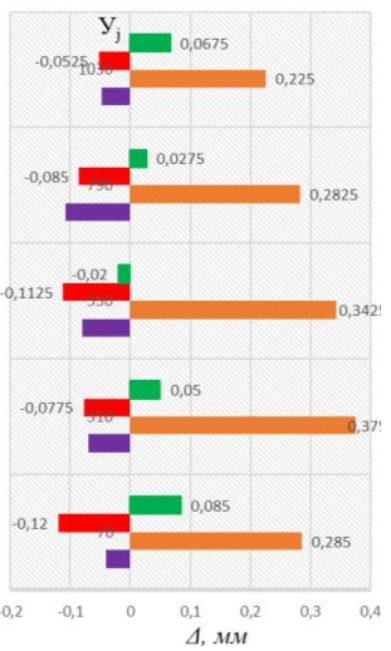

e)

ша выходе стури (Л)

ш на входе струи (Л)

ш на выходе струи (П)

- на входе струи (П)

Fig. 6. Dependences of changes in the the diameter dimensionsdeviations from the nominal ones along the $\mathrm{Y}$-axis ( $\Delta$-deviations of the diameter dimensions on the $\mathrm{y}$-axis, $\mathrm{mm}$; $\mathrm{Y}_{\mathrm{i}}$-coordinates along the $\mathrm{Y}$-axis, $\mathrm{mm}$ ).

Analyzing the dependence of the variation of the deviation from the nominal dimensions along the y axis, it can be noted that the most accurate holes were obtained in part 1 of the right fraction. The hole with the least accuracy was obtained in part 4 of the left fraction.

Analyzing the design features and technological properties of waterjet cutting, it can be noted that the accuracy of manufacturing parts using WJC is a multi-factor value. Therefore, it is necessary to optimize the parameters that greatest influence on the processing accuracy.

First of all, the accuracy and quality of processing during waterjet cutting are affected by the rigidity of the tool positioning system. Therefore, it is necessary to take into account the rigidity 
of the cutting head movement device of the waterjet machine. In order to determine the rigidity of the waterjet cutting head movement device, a number of experiments were performed.

The ability of an elastic system with WJC to resist the action of forces that tend to deform it is called the rigidity of a waterjet system. High rigidity of the waterjet system is one of the main conditions for achieving high accuracy ofprocessing. In the absence of sufficient rigidity under the action of cutting and other forces during waterjet processing, it is deformed, which leads to distortion of the shape of the part and the appearance of size deviations. The vibration phenomenon is related to the rigidity of the positioning system of the waterjet tool. Systems with high rigidity can operate in high-performance cutting modes without vibration.

The stiffness of the tool positioning system is expressed as the ratio of the cutting force component acting in the direction normal to the treated surface to the mutual displacement of the cutting tool and the workpiece, counted in the same direction:

$$
j_{i}=\frac{P_{i}}{y}
$$

where, $j_{i}$ is therigidity of the tool positioning system, $\mathrm{kN} / \mathrm{mm}$;

$\mathrm{P}_{\mathrm{i}}$ is theexternal load, $\mathrm{kN}$;

$\mathrm{y}$ is the deformation of the elastic system, $\mathrm{mm}$.

When evaluating the manufacturing accuracy ofwaterjet cutting, the rigidity of the positioning device ofthe waterjet cutting tool on different planes in relationto different axes was studied. Figure 7 shows the selected coordinate system for determining the static stiffness of the positioning system ofthe waterjet cutting tool.

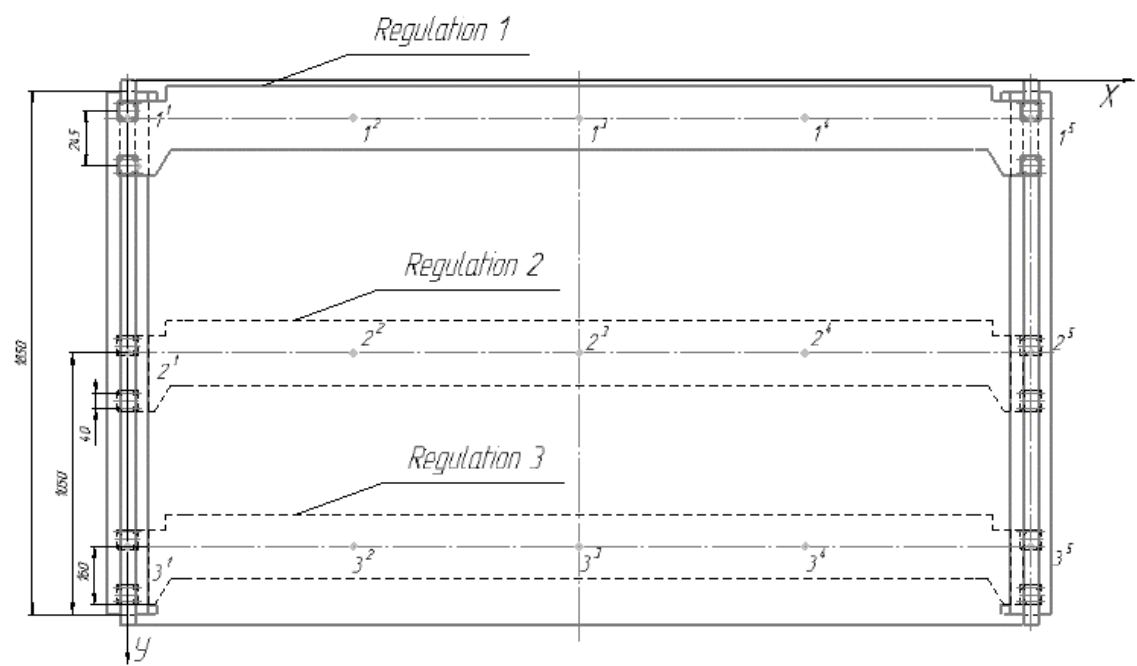

Fig. 7. Coordinate systems of the WJC platform for drawing up a diagram of the installation of measuring instruments in three positions on the $\mathrm{x} 0 \mathrm{y}$ plane relative to the $\mathrm{z}$-axis.

The coordinate system of a WJC platform consists of five points. When determining the static stiffness of the positioning system of the waterjet cutting machine, the stiffness $X_{z}$ and $\mathrm{Y}_{\mathrm{z}}$ were determined. According to the data obtained, a diagram of the static stiffness of the displacement device on the XOY plane was compiled (Fig.8). In this diagram, onecan seethat the 
$\mathrm{Y}_{\mathrm{z}}$ stiffness is high compared to $\mathrm{X}_{\mathrm{z}}$. The rigidity of the travel device along the $\mathrm{Y}$-axis (points $1^{1}$, $\left.2^{1}, 3^{1}\right)$ at the beginning of the zone is less than at the end of the zone.

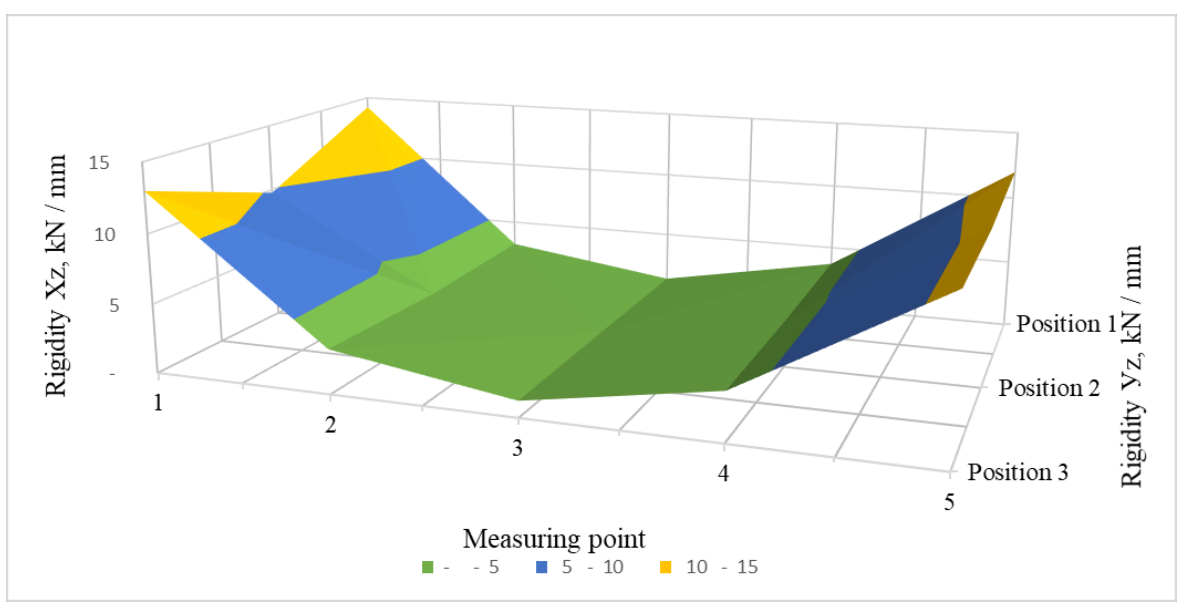

Fig. 8. Diagram of static stiffness of the moving device on the $\mathrm{x} 0 \mathrm{y}$ plane relative to the $\mathrm{Z}$ axis $(\mathrm{Xz}$ and Yz).

The static stiffness of the system for moving the cutting head of the waterjet unit on the X0Z plane relative to the $\mathrm{Y}\left(\mathrm{X}_{\mathrm{y}}\right)$ axis was also measured. Based on the obtained measurement results, a graph of static $X_{y}$ stiffness was plotted (Fig. 9). Analyzing this graph, we can note that the static stiffness $\mathrm{X}_{\mathrm{y}}$ in the middle of the waterjet cutting head movement system is not high.

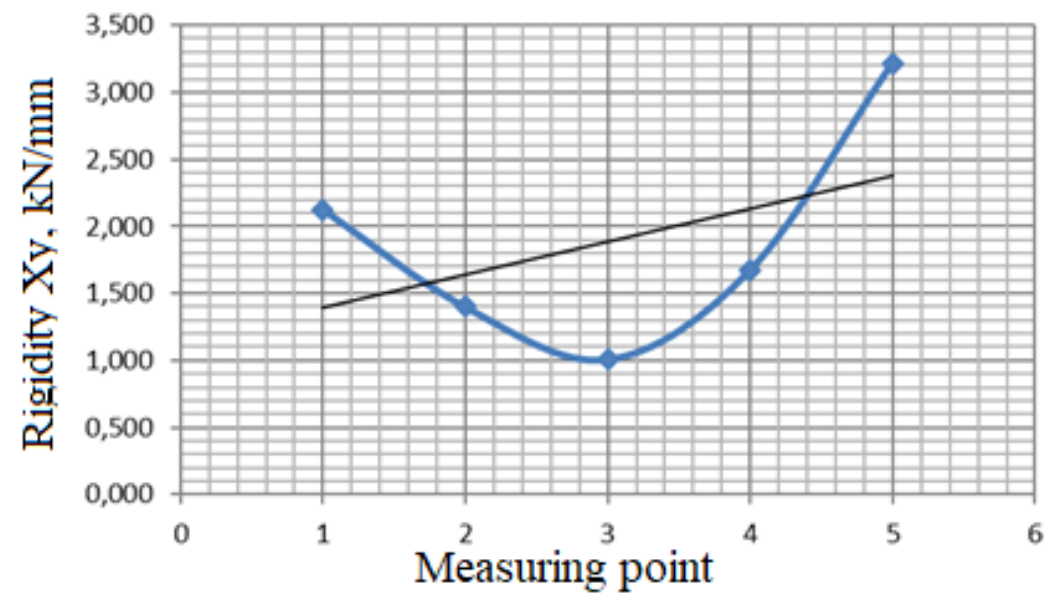

Fig. 9. Graph of static stiffness of the moving device on the $\mathrm{XOZ}$ plane relative to the $\mathrm{y}(\mathrm{Xy})$ axis

In the course of the experimental study, the rigidity of the system was determined for the cutting head of a waterjet machinemoving on the $\mathrm{X} 0 \mathrm{Z}$ plane relative to the $\mathrm{Y}\left(\mathrm{Z}_{\mathrm{y}}\right)$ axis and on the $\mathrm{Y} 0 \mathrm{Z}$ plane relative to the $\mathrm{X}\left(\mathrm{Z}_{\mathrm{x}}\right)$ axis (Fig.10). 

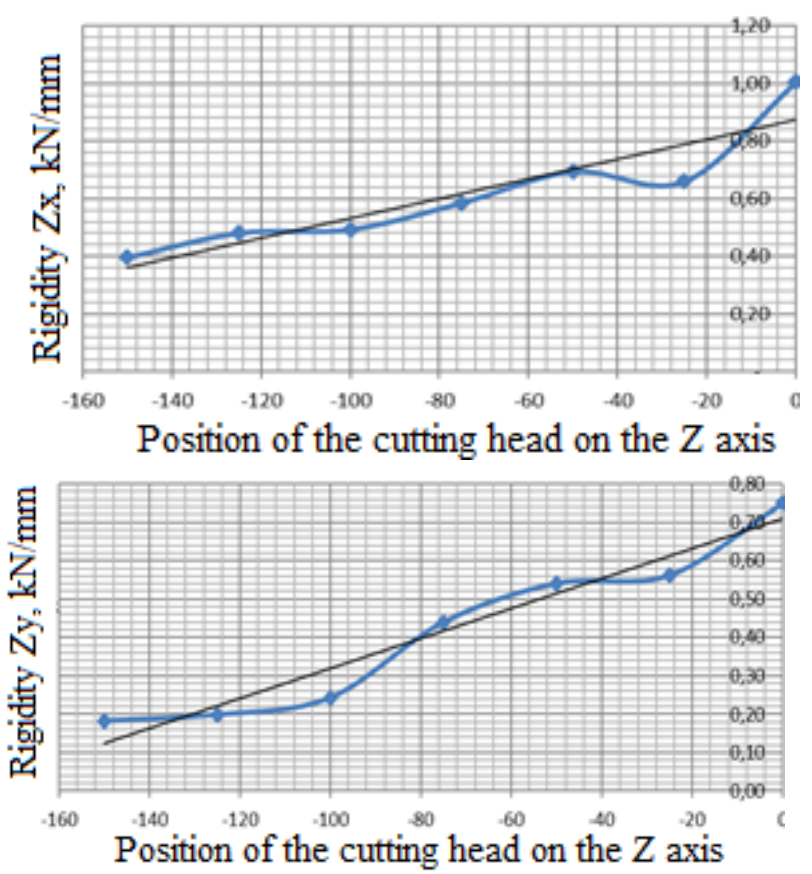

Fig. 10. Graph of static stiffness of the moving device on the Y0Z plane relative to the $\mathrm{x}$-axis $(\mathrm{Zx})$ and static stiffness of the moving device on the $\mathrm{X} 0 \mathrm{Z}$ plane relative to the $\mathrm{Y}$-axis $(\mathrm{Zy})$.

\section{Conclusions}

The errors that arise during waterjet processing are a significant factor in the formation of errors in the subsequent processing of the product (technological inheritance). From the conducted study, it was foundthat the accuracy of processing during waterjet cutting primarily depends on the rigidity of the tool positioning system, namely, the rigidity of the portal system for moving along the $\mathrm{X}$ and $\mathrm{Y}$ axes. The rigidity of the tool positioning system directly affects the accuracy and quality of the resulting product. During a number of experiments it was found that the resulting errors in the WJC are systematic, the nature of the errors corresponds to the nature of deformations of the displacement device.

To increase the accuracy and improve the quality of processing ofwaterjet cutting, it is necessary to ensure uniform system stiffness or change the cutting modes depending on the system stiffness.Thus, in some other works [8-11], a mathematical model of the WJCmachinewas developed. In the future, it is planned to modernize the installation based on the results of optimizing the parameters of the mathematical model. Also, the introduction of a system for correcting the deviation of the cutting jet prigar at different cutting zones will improve the accuracy of manufacturing and the surface quality of the resulting product.

\section{References}

1. On the strategy of innovative development of the Russian Federation for the period up to 2020. [Electronic resource]: Decree of the Government of the Russian Federation No. 2227-R of December 8, 2011-access mode:

2. https://www.garant.ru/products/ipo/prime/doc/70006124/\#review (25.09.2019). 
3. G. V. Barsukov Improving the efficiency of waterjet cutting on the basis of discrete regulation of the technological system states. (Dissertation for the degree of doctor of engineering. Orel, 2006).

4. A. Gapeyevtsev Marketing ensuring ofthe competitiveness of products of tool industry enterprises. (Dis. Cand. Econ. science: 08.00.05: Moscow, 1998)

5. S. N. Polyansky Technology and equipment of waterjet cutting, Bulletin of Mechanical Engineering, 5, 43-46 (2004).

6. Precision modeling technologies / Waterjet cutting. Technology [Electronic resource] URL: https://ttm66.ru/news/istoriya-gidroabrazivnoj-rezki (accessed 24.04.2019).

7. Yu. a. Morgunov, A. A. Fedotov, D. V. Shvychkov Application of waterjet cutting in the processing of complex surfaces of parts. (MSTU MAMI).

8. Yu. N. Kolmoyrov Methods and means of scientific research: textbook. Manual. (Yekaterinburg: Ural Publishing House. UN-TA, 2017).

9. Yu. S. Stepanov, G. V. Barsukov Modern technological processes of mechanical and hydrojet cutting of technical fabrics. (M.: Mashinostroenie, 2004).

10. Sh. S. Nozirzoda Study of the effect of stiffness on the accuracy and quality of parts received for the installation of waterjet cutting: master thesis, School of Engineering of New Production Technologies (2020).

11. Sh. S. Nozirzoda Investigation of the manufacturing accuracy of the "suspension" part during waterjet treatment of stainless steel, Young Russia: materials of 11th all-Russian scientific-practical conference with international participation, (2019). 